\title{
World grapples with climate change
}

A

lthough for years a small number of scien-

tists argued to the contrary, today there is a scientific consensus that global climate change is well under way.

New and unexpected evidence of global warming came in February and March, as an ice shelf believed to be 12,000 years old collapsed into the Weddell Sea. This huge Antarctic ice shelf - 650 feet thick and covering 1,250 square miles

- disintegrated into thousands of icebergs.

Scientists were staggered by the speed of the ice shelf's collapse. "It's hard to believe that 500 billion tons of ice sheet has disintegrated in less than a month," David Vaughn of the British Antarctic Survey said.

The collapse of Larsen B ice shelf was just the latest news about global warming and its impacts. Scientists with UC San Diego's Scripps Institution of Oceanography announced in February that the temperature of the Southern Ocean - which surrounds Antarctica - has increased by a third of a degree in the past halfcentury. The Southern Ocean is apparently warming faster than the rest of the world's oceans.

"We can think of it as a canary in a coal mine telling us what may happen to the global climate," said Scripps Assistant Professor Sarah Gille, whose research was published in the journal Science. A warmer Southern Ocean "could be exchanged into all of the ocean basins and into the latitudes where people live."

Meanwhile, the U.S. National Climate Data Center announced in February that the United States was in the midst of its warmest winter on record. The national average temperature of $39.94^{\circ} \mathrm{F}$ for November 2001 through January 2002 was $4.3^{\circ} \mathrm{F}$ above the $1895-2001$ average. According to National Aeronautics and Space Administration (NASA) data, the 10 warmest years on record have occurred since 1980.

\section{International science panel}

In 1988, the World Meteorological Organization and the United Nations Environment Programme established the Intergovernmental Panel on Climate Change (IPCC), an international network of hundreds of scientists that assess scientific aspects of climate change and evaluates mitigation options. In its Third Assessment Report, released in 2001, IPCC concluded that "there is new and stronger evidence that most of the warming observed over the last 50 years is attributable to human activities" (see p. 89).
The atmospheric concentrations of key greenhouse gases in the atmosphere - carbon dioxide, methane, nitrous oxide and ozone reached record levels in the 1990s, IPCC found, "primarily due to the combustion of fossil fuels, agriculture and land-use changes."

According to the IPCC, certain facts about global warming are known:

- Since the period 1000-1750, atmospheric concentrations of carbon dioxide have increased from 280 parts per million (ppm) to $368 \mathrm{ppm}$.

- The Earth's global mean surface temperature has increased approximately $1.1^{\circ} \mathrm{F}$ during the 20th century.

- The Earth's global mean sea level has increased at an average annual rate of 1 to 2 millimeters per year during the 20th century; meanwhile, the extent and thickness of Arctic sea ice in spring and summer decreased $10 \%$ to $15 \%$ since the 1950 s.

\section{Global responses}

However, considerable scientific and political controversy remains over the extent of the expected changes, how quickly they will occur, and what should be done, if anything.

In 1979, the First World Climate Conference - a scientific gathering - recognized climate change as a serious problem, issuing a declaration calling on the world's governments to "foresee and prevent potential man-made changes in climate that might be adverse to the well-being of humanity." A series of international meetings and

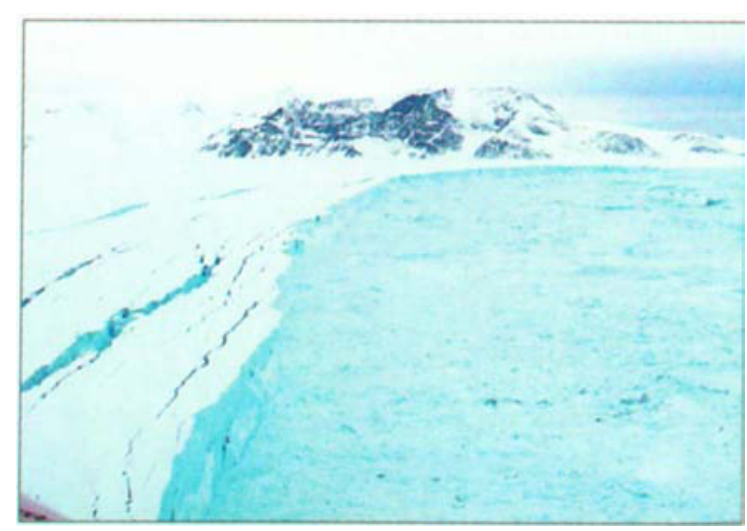

The northern section of the Larsen B ice shelf, a huge floating ice mass on the eastern side of the Antarctic Peninsula, shattered and separated from the continent over a 35-day period beginning Jan. 31, 2002. Scientists were stunned by the speed of its disintegration, and viewed the event as further evidence of global warming. The ice shelf's new front line was photographed on March 13, 2002, by S. Tojeiro, Fuerza Aerea Argentina. 
scientific conferences followed.

The most significant, broad-based global approach to emerge is the Kyoto Protocol to the United Nations Framework Convention on Climate Change. Agreed upon at a 1997 meeting in Kyoto, Japan, the protocol seeks to reduce greenhouse gas emissions by an average of $5.2 \%$ below 1990 baseline levels, by 2012. (The IPCC provided key scientific input.) The protocol must be ratified by 55 nations to enter into force; as of March 28, 2002, 84 nations had signed the agreement and 51 had ratified it.

In March 2001, President Bush made headlines around the world when he announced that the United States, which is responsible for nearly a quarter of the world's carbon emissions, would not sign the Kyoto Protocol. In a subsequent speech, he termed the protocol "fatally flawed in fundamental ways."

"For America, complying with those mandates would have a negative economic impact, with layoffs of workers and price increases for consumers," Bush said.

In February 2002, President Bush announced his administration's new strategy for "an effective and science-based response to the issue of global warming." Rather than setting manda-

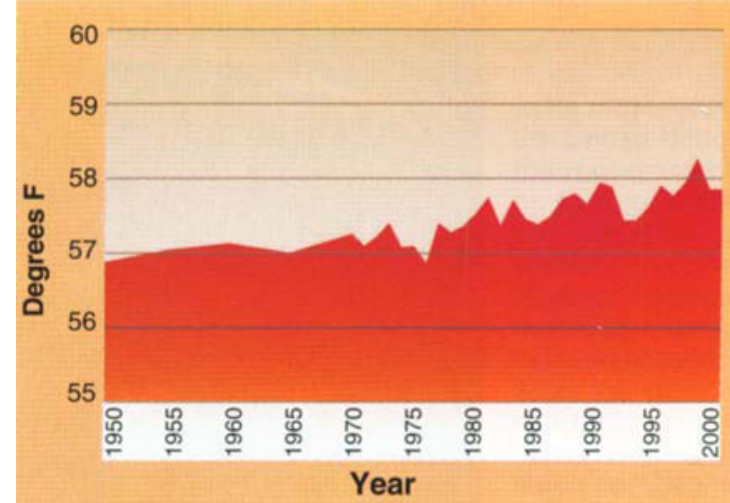

Global average temperature, $1950-2000$. Source: Goddard Institute for Space Studies. tory reduction targets, the plan relies on research, new technology, emissions trading and tax incentives to promote voluntary emissions reductions.

Despite global discussion and efforts for more than two decades, emissions of important greenhouse gases have not substantially declined. Since 1990, Western industrial nations have increased

\section{Satellites provide more accurate climate change data}

\section{El Niño heats Pacific Ocean}

This globe represents the capabilities of NASA's EOS Terra satellite, launched in December 1999, which views the Earth with multiple sensors and a series of interrelated instruments. The red swath in the center is the warm waters of the sea surface that occur in the eastern Pacific Ocean during an EI Niño event. Some scientists predict that EI Niños will occur more frequently due to global warming, resulting in more floods and droughts. The satellite data is helping scientists understand the cause-and-effect relationships among Earth's lands, oceans and atmosphere in order to better predict what, if any, impacts rapid changes will have on future climate conditions. Image by R.B. Husar, Washington University; land layer from the SeaWiFS Project; fire maps from the European Space Agency; sea surface temperature from Naval Oceanographic Office's Visualization Laboratory; and cloud layer from SSEC, University of Wisconsin.

\section{Sea surface heights rising}

This globe shows imagery from the U.S.-French TOPEX/Poseidon satellite (NASA Jet Propulsion Laboratory), illustrating a giant horseshoe pattern of higher than normal sea surface heights that has developed in recent years and is beginning to dominate the entire western Pacific and Asiatic oceans. Taken between Dec. 30, 1999, through Jan. 8, 2000, the data show that this slow-developing condition covers most of the Pacific Ocean. Sea surface height is shown relative to normal (green) height and reveals cooler water (blue and purple) between 3 and 9 inches lower than normal along Central and South American coasts, and stretching out into the equatorial Pacific. The giant horseshoe of warmer water (red and white) dominating the western and midlatitude Pacific has higher than normal sea surface heights of between 3 and 9 inches.

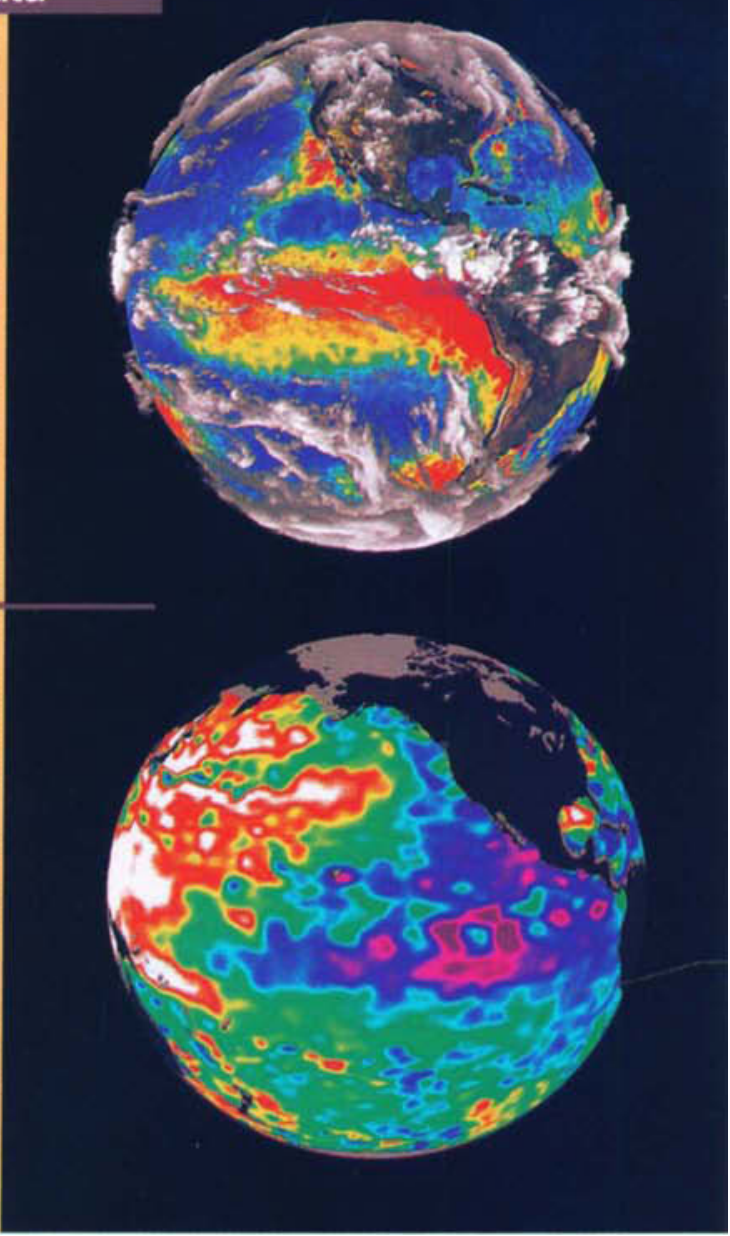


their carbon emissions by $9.2 \%$ and developing nations by $22.8 \%$. The United States now emits 13\% more carbon than it did in 1990.

\section{Looking ahead}

Nonetheless, there are signs that the international community is taking the problem seriously. At a meeting in Bonn, Germany, in July 2001, representatives from 178 nations finalized many of the protocol's key rules, without the participation of U.S. negotiators. The World Summit on Sustainable Development, scheduled for September 2002 in Johannesburg, South Africa, will provide another opportunity for the world's nations to move the climate change agenda forward.

With or without an international agreement, significant progress has also been made in developing new technologies and market mechanisms such as emissions trading. In its 2001 assessment, the IPCC found that there are "many opportunities including technological options to reduce near-term emissions." The IPCC pointed to a portfolio of technologies that have developed "faster than anticipated." They include more effective energy use, shifts

\section{Anticipated impacts of climate change}

In its 2001 assessment of current science on global warming, the Intergovernmental Panel on Climate Change (IPCC) determined that current and anticipated impacts include:

- More hot days and higher heat indexes.

- Fewer cold/frost days.

- Increases in precipitation over the Northern Hemisphere, and possible decreases in other regions (parts of Africa and the Mediterranean).

- Heavier precipitation events and more severe droughts.

- Retreat of nonpolar glaciers.

- Thawed, warmed and degraded permafrost in parts of the polar, subpolar and mountainous regions.

- Decreases in snow cover.

- Lengthened growing seasons.

- More frequent El Niño weather events.

- Earlier plant flowering, bird arrival, dates of animal breeding and emergence of insects.

- More coral reef bleaching, especially during EI Niño events. to technologies that emit less or no greenhouse gases, carbon removal and storage, improved land use and forestry practices, fuel cells and better wind turbines.

The Worldwatch Institute estimated that in 2000, global carbon emissions from fossil fuel combustion dropped by $0.6 \%$ to just under 6.3 billion tons, the third consecutive year of decline. The world's estimated amount of carbon emitted per unit of economic output also fell by $3.6 \%$ in 2000 . Furthermore, a number of major companies, such as Alcoa, Dow Chemical, DuPont and Toyota, have voluntarily set targets for reducing or eliminating greenhouse gas emissions.

The IPCC scientists warned, however, that successful implementation of available and evolving mitigation options would need to overcome a variety of barriers that currently prevent their full exploitation.

In California, the state Assembly passed a bill in January 2002 (AB 1058), which would require reductions in carbon dioxide emitted by cars and light trucks. With about $10 \%$ of the nation's new car sales, California in turn accounts for about $2 \%$ of global carbon dioxide emissions.

Urging passage of the bill, several dozen UC scientists joined their colleagues in a letter to Governor Davis and members of the state legislature.

"Critical economic drivers in the state, including agriculture, fishing, tourism and timber industries may see devastating reductions in productivity [resulting from global climate change]," they wrote. "We believe the state's immediate implementation of policies to control global gas emissions represents sound public policy based on virtually irrefutable scientific evidence." - Janet Byron

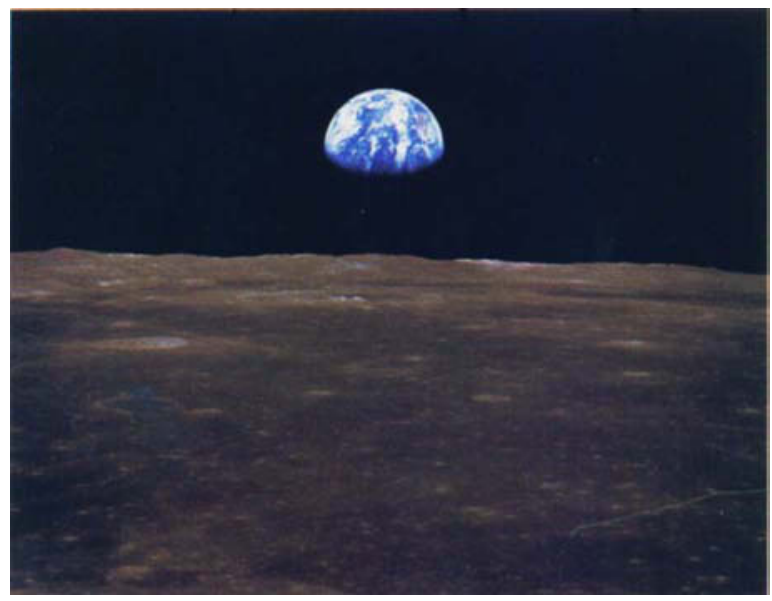

Earthrise from the moon, taken by the Apollo 11 mission in 1969. 